\title{
Stakeholder Perceptions on Graduation in Ethiopia and Rwanda*
}

\author{
Stephen Devereux and Martina Ulrichs
}

\begin{abstract}
The Food Security Programme in Ethiopia and the Vision 2020 Umurenge Programme in Rwanda deliver a combination of consumption support (cash or food transfers, Public Works employment) and livelihood support (asset packages, microfinance) with the objective of 'graduating' rural households out of food insecurity and poverty into self-reliant livelihoods. This article presents perspectives on graduation of influential stakeholders in Ethiopia and Rwanda, and draws conclusions from these case studies for global graduation debates. Our qualitative research reveals a diversity of opinions about the complexity of factors that enable or constrain sustainable graduation. These relate partly to programme design, but also to implementation issues and the different national and subnational economic, political and agroecological contexts within which programmes operate. The alignment of graduation with broader development goals makes investment in these programmes attractive to donors as well as governments, but risks introducing excessive political pressure to demonstrate 'success'.
\end{abstract}

\section{Introduction}

The governments of Ethiopia and Rwanda have introduced programmes that have similarities with the 'graduation model' that was pioneered in Bangladesh in the early 2000s by BRAC, one of the world's largest non-governmental organisations (NGOs). Graduation programmes deliver a sequenced package of consumption and livelihood support to extremely poor households, including cash or food transfers, productive assets such as livestock, access to microfinance (savings and credit) and livelihood training plus life coaching. Evaluations of BRAC's

'Challenging the Frontiers of Poverty Reduction' programme have found impressive success rates, with up to 95 per cent of programme participants graduating out of extreme poverty after just 24 months of support (BRAC 2013).

Ethiopia's Food Security Programme (FSP) and Rwanda's Vision 2020 Umurenge Programme (VUP) share almost identical design features (Table 1). In both cases, consumption support, delivered either as unconditional cash or food transfers to individuals who are unable to work ('Direct Support'), or as payment for working on community infrastructure projects to individuals who can work ('Public Works'), performs the social protection role of stabilising income and consumption through difficult months or years. These interventions are complemented by livelihood support, delivered either as asset packages in Ethiopia or as low-interest loans for income-generating activities in Rwanda, which aims to raise household income and facilitate sustainable exit from these programmes within 2-5 years.

Graduation is defined in relation to the targeting criteria in each case - chronic food insecurity in Ethiopia (households are eligible if they received food aid in each of the last three years) and 'social poverty' in Rwanda (eligible households are those classified in the bottom two 'Ubudehe' wealth categories by a community ranking exercise) (see Sabates-Wheeler et al., this IDS Bulletin). In Ethiopia: 'A household has graduated when, in the absence of receiving PSNP [Productive Safety Net Programme] transfers, it can meet its food needs for all 12 months and is able to withstand modest shocks' (FSCB 2007: 1). In Rwanda: 'Households exit from direct support and public works when they move into Ubudehe category 3 or above and therefore are no longer eligible for direct support transfers or public works wages' (MINALOC 2011: 2). 


\begin{tabular}{lll}
\hline Programme component & Ethiopia (FSP/PSNP) & Ruanda (VUP) \\
\hline Targeting & Chronic food insecurity & Extreme social poverty \\
\hline Consumption support & $\begin{array}{l}\text { Cash or food transfers } \\
\text { (Direct Support) }\end{array}$ & $\begin{array}{l}\text { Cash transfers } \\
\text { (Direct Support) }\end{array}$ \\
\cline { 2 - 3 } & Cash or food wages & Cash wages \\
& (Public Works) & (Public Works) \\
\hline Livelihood support & Household Asset-Building Programme (HABP) & Ubudehe Credit Scheme (UCS) \\
\hline Training & Extension services & Community Sensitisation \\
\hline
\end{tabular}

Source Authors' own.

To understand the evolving perspectives on graduation in Ethiopia and Rwanda, the authors conducted semi-structured interviews with 38 key stakeholders in both countries. Respondents included government officials involved in policy formulation and programme management, staff from development partners (donor agencies and international financial institutions) who provide financial and technical assistance to these programmes, international or local NGO workers involved in programme or project implementation, and researchers active in programme evaluations. ${ }^{2}$ The data presented in this article are the voices of these individuals, in the form of direct quotations transcribed from our interviews.

Research questions included:

Is graduation an appropriate and feasible objective for social protection programmes, or does the emphasis on livelihood 'promotion' risk crowding out the primary emphasis on 'protection'?

- What are the main 'enablers' and 'constraints' to graduation in the national and subnational contexts where interviewees are working? ${ }^{3}$

The next two sections of this article address these two questions, before Section 4 concludes.

\section{Should graduation be an objective of social protection programmes?}

An ongoing debate in the literature questions whether the primary purpose of social protection is to deliver social assistance that alleviates extreme poverty (a social welfare function) or livelihood support that lifts people out of extreme poverty altogether (a poverty reduction function). Barrientos (2010: 2) argues that social protection should serve both objectives: '(i) to help protect basic levels of consumption among those in poverty or in danger of falling into poverty; (ii) to facilitate investment in human and other productive assets which alone can provide escape routes from persistent and intergenerational poverty'. Other commentators put more emphasis on the second function: 'Governments around the world are increasingly focused on the "promotion" function of their social protection systems... Part of the concern is related to the potential dependency on benefits, incentives for beneficiaries to stay or become inactive, and the fiscal cost of the transfer' (Ameida et al. 2012: 2). These arguments have been criticised as reflecting 'neoliberal' motivations. 'The desire by some governments to "graduate" people from poor relief schemes is directly related to their perception of such schemes as "handouts" and a desire not to create "dependency". Such views are embedded within a neoliberal vision of social policy, which aims to limit investment on social security by exiting people from the system' (Kidd 2013: 3).

We asked stakeholders in Ethiopia and Rwanda for their views. Should graduation be an objective of social protection programmes at all? The dominant view in both countries seems to be that comprehensive social protection should perform both 'livelihood protection' and 'livelihood promotion' functions. Within this broad consensus, however, a number of more nuanced positions can be discerned, ranging from those aligned with 'neoliberal' values (avoid dependency, minimise spending) through to a less frequently articulated 'social justice' perspective (graduation contradicts the right to social protection), with the 'twin-track' view 
falling in the middle (graduation is possible for some, but permanent social assistance is essential for others).

The neoliberal perspective was reflected by some government officials and development partners (donor and NGO staff) who argued the case for rigorous targeting and graduation as an 'exit strategy', to ensure that the neediest people receive support for a limited period only, otherwise - they claim - financial constraints will make social protection unsustainable. Graduation is therefore seen as strategically important, to avoid dependency and to keep social protection financially affordable by minimising the social assistance caseload.

Sometimes social protection, unless it is properly targeted, it may become a source of laziness (Local NGO worker, Ethiopia).

If you don't graduate people then we can't reduce poverty, so we need to have a strong focus on graduation (Government official, Rwanda).

Graduation should be for all. We shouldn't create dependency. Graduation is a way of people taking care of themselves, not being a burden on the country. It is also important for revenue reasons - it is difficult to pay for these programmes in the context of a lowincome country (Development partner, Rwanda).

An increasing concern for development partners is to achieve 'value for money' from their aid spending, in terms of measurable and attributable impacts of the programmes they support. Building graduation targets into programme design provides a benchmark against which progress can be measured. It also provides an end-date for financial support to these programmes. Graduation demonstrates 'successful' interventions by governments, donors and NGOs, and justifies the relatively high levels of spending on these programmes. This is politically beneficial for governments as well as their development partners.

Politically, graduation makes social protection palatable (Development partner, Rwanda).

There is a clear focus of donors on graduation, as well as for the government. It is an easy way to go because you want to measure outcomes. It is a taxpayer-donor incentive. And it is the same for the government (Researcher, Ethiopia).
Some donors and international NGO staff were highly critical of graduation as an aspiration, and admitted that their agencies support graduation only because there was no other way to convince the government to accept some form of social protection. In Ethiopia especially, the concept of a 'productive' safety net seems to have been a compromise to get social protection onto the national policy agenda despite the government's strong resistance to social welfare programmes, which it associates with annual emergency aid appeals and free food 'handouts'.

On the other hand, there is an increasing recognition, even among policymakers who are concerned about dependency and the fiscal implications of social protection programmes, that graduation is only appropriate and feasible for households that have the capacity to aim for self-reliance. For others, especially vulnerable groups such as persons with severe disability, permanent safety nets may be needed and there should be no expectation of graduation.

Graduation comes only after safety nets have been established, and the graduation pathway is mainly open to those who can take advantage of these opportunities. We don't forget those who cannot benefit. Like children living alone or old people, people with mental disabilities, we don't forget them, we don't expect them to work (Government official, Rwanda).

This 'twin-track' approach is reflected in the design of the FSP in Ethiopia and VUP in Rwanda. Both programmes provide Public Works employment, assets and microcredit to poor households with labour capacity, and unconditional cash transfers to poor households with negligible labour capacity.

Several respondents in both countries also pointed out that graduation was never expected to be achieved through cash or food transfers alone. Graduation can only be achieved through a holistic 'package' of interventions. One of the biggest challenges identified to sustainable graduation, in both countries, is that participants typically graduate 'out of' the FSP and VUP, instead of 'into' other programmes. The lack of complementary programmes post-graduation increases the likelihood that 'graduates' will fall back to pre-graduation levels. 
The government itself would like to be seen as moving to broader social protection programmes. And within that you will also have graduation, moving in and out from the different programmes in the system. We have to have it, but it has to make sure that households don't fall back (Development partner, Ethiopia).

It is not just social protection that graduates people, it is a combination of programmes like nutrition programmes, health insurance, school feeding, microfinance... So you have to talk about graduation not as an end in itself but as part of the big agenda for social protection becoming a stepping stone to development (Government official, Rwanda).

Some respondents went further, arguing that graduation is not the responsibility of social welfare or safety net programmes and should not be part of social protection systems. Graduation programmes and social protection programmes have entirely different objectives. Social protection aims to protect vulnerable people against risks, while graduation aims to increase the productivity of the working poor and integrate them into the labour market. The concept of 'productive safety nets' is thus a contradiction in terms.

It is important to sort out the division of labour between social protection programmes and more development-oriented programmes. In most cases, interventions and activities that are geared towards graduation fit more naturally into agricultural programmes, access to credit, education, etc., than social protection (Development partner, Rwanda).

By this logic, graduation-oriented programmes and social protection programmes should be two different types of interventions targeting different categories of people with differentiated policy instruments. This 'twin-track' thinking informs recent proposals for transferring Ethiopia's Direct Support beneficiaries from the Ministry of Agriculture and Rural Development - which would continue to administer the Public Works component of the PSNP - to the Ministry of Labour and Social Affairs (Devereux and Teshome 2013). It might be no coincidence that similar views are also being heard in Rwanda.

We have a contradiction between the focus on graduation and trying to reduce the numbers on VUP when the needs are actually increasing. Maybe VUP should focus only on the most vulnerable - those on
Direct Support - for social protection, and those now doing Public Works should get support from something else, not social protection (Development partner, Rwanda).

Even if graduation is accepted as a valid objective for social protection, there is some concern that an increasing preoccupation with graduating or 'exiting' participants out of social protection programmes could detract attention from their primary purpose, which is 'protection' rather than 'promotion' - in other words, that the secondary objective is becoming the primary objective. A government official from Rwanda denied that this is a risk, since graduation and safety nets are not mutually exclusive, but complementary. Safety nets will persist while graduation programmes will help beneficiaries to reduce their reliance on them by increasing their assets and accessing markets.

The graduation component is added to the safety net to ensure there is a progressive trend taking place. The objective of social protection is not graduation, it is to protect those households who are in poverty, but the graduation component is a stimulus to those who can get out (Government official, Rwanda).

\section{Graduation enablers and constraints}

The questionnaire designed for the qualitative research asked interviewees to identify and explain the factors that facilitate or inhibit graduation in Ethiopia and Rwanda, drawing on a typology of 'enablers and constraints' developed by Sabates-Wheeler and Devereux (2013). Their framework disaggregates determinants of graduation into five categories or levels, four of which are examined here: programme, market, environment and beneficiary. Instead of the fifth category - community - we added the political level, since incentives or disincentives at the political level to push for a graduation agenda strongly affect graduation outcomes in both countries. This section presents stakeholders' narratives on enablers and constraints to graduation at these various levels.

\subsection{Programme level}

The design features and implementation modalities of graduation programmes are crucial determinants of their outcomes. In terms of programme design, it was recognised that the amounts of cash or food transferred by the PSNP and VUP are not large enough for participants to 
graduate in either case. Budget constraints were given as the reason why payments have not been raised to enhance graduation potential.

People think first of food and paying 'mutuelle de santé' [compulsory health insurance contributions]. This leaves too little remaining for investment... We have financial constraints. Increasing the payment level while still expanding the programme every year is not possible (Government official, Rwanda).

In Rwanda, Direct Support beneficiaries - who are considered less likely to graduate, because of their labour constraints - receive higher payments than Public Works participants, because Direct Support payments are calibrated by household size but Public Works payments are not.

Direct Support is based on household size and is quite a big transfer. The maximum household size it pays for is five. Public Works is not calibrated by household size, it is a daily wage rate and you only get one workplace per household. There was nervousness about relating Public Works payments to household size, especially that it might distort fertility choices and encourage larger families (Development partner, Rwanda).

Also at the programme level, the effectiveness of complementary interventions is seen as decisive for graduation potential. Most households engaged in Public Works, and a minority of those receiving Direct Support transfers, are expected to take advantage of other types of support notably the Household Asset-Building Programme (HABP) in Ethiopia and the Ubudehe Credit Scheme (UCS) in Rwanda - to propel them further up the graduation ladder.

However, respondents in Ethiopia pointed out that there is regional variation in the quality of implementation of these complementary interventions, which partly explains differences in programme performance and graduation outcomes across regions. For instance, in Tigray the linkages between the PSNP and HABP generally work well due to strong regional leadership and implementation capacity. But in other regions, where access to HABP is restricted due to a combination of political incentives that lead to inefficient allocation of funds and weak implementation, graduation potential is compromised. Failure to successfully link the PSNP and HABP was considered to be one of the main obstacles to graduation.
PSNP graduates are meant to be taken up by the $H A B P$, but that has not really worked. Few households access credits. This means that they fall back to the PSNP or the humanitarian programme. The biggest challenge of the PSNP is that the HABP did not really deliver as expected (Researcher, Ethiopia).

A related challenge identified to the sustainability of graduation, in both countries, is that participants typically graduate 'out of' the PSNP and VUP, instead of 'into' other programmes.

For people to graduate from PSNP by itself is not enough, there have to be some complementary activities. But are these graduated people getting other types of assistance? So their chances of falling back are really, really high, unless the programme makes sure that graduates are continuously getting other programme support (Development partner, Ethiopia).

It is not just social protection that graduates people, it is a combination of programmes like nutrition programmes, health insurance, school feeding, microfinance, and by investing all this into poor households we expect that many of them will benefit, and so you have to talk about graduation not as an end in itself but part of the big agenda for social protection becoming a stepping stone to development (Government official, Rwanda).

\subsection{Market and environmental levels}

At the market level, it was acknowledged that programme participants need to have access to well-functioning markets if they are to grow their incomes, yet the rural economy is not sufficiently developed in either Ethiopia or Rwanda. In terms of environmental constraints, difficult agroecological conditions and an erratic climate, especially in Ethiopia, undermine the productivity of agriculture and related livelihood activities, and discourage investment in enterprises that could be devastated by drought. For this reason, the wider context - in this case, rural infrastructure and the natural resource base - is crucial for graduation potential. It is unrealistic to expect programmes such as the FSP or VUP to create the favourable enabling context required.

There are many factors outside of the programme that really affect the outcomes. Market linkages and access to inputs really affects them, access to information, even infrastructure. Some of the beneficiaries live in 
very remote areas. Having a graduation type of model, will it work in that context when they are very isolated from the society? If you design a graduation or livelihood diversification programme it has to look at the context (Development partner, Ethiopia).

Weak markets and rural poverty create a risky environment for introducing new livelihood options, or for rapidly expanding the scale of local income-generating activities. The challenge of limited demand for rural produce was faced when the HABP promoted honey production in Ethiopia, and when tomato production expanded in Rwanda.

People's innovative capacity is low, so what often happens is that people copy each other and this affects the market. One person starts growing tomatoes and everyone else in the village does the same, then they flood the market and the price collapses, so next season they leave tomatoes and all try something else (Government official, Rwanda).

\subsection{Beneficiary level}

Stakeholder perceptions of beneficiary-specific enablers and constraints reflect two contrasting narratives. The first assumes that beneficiaries want to graduate, but lack the necessary attributes or resources to do so. The second challenges the assumption that graduation is a desirable objective for beneficiaries, asserting instead that they will try to stay in the programme and avoid being 'graduated' so as not to lose their benefits.

\section{Beneficiaries want to graduate but lack confidence and resources to do so}

In both countries government officials asserted that beneficiaries want to graduate. Rwandan officials claimed that beneficiaries and communities see graduation as a positive achievement. Ethiopian officials argued that most PSNP participants want to graduate, because awareness-raising sessions have been conducted to communicate what graduation means and how it will occur.

Generally their attitude to graduation is positive. Most people do want to graduate. They all want to achieve something and move a step ahead (Government official, Rwanda).

The guidelines are clearly shown and the benchmarks are explained. The beneficiary has to believe in that benchmark, because the government's aspiration is to graduate beneficiaries. Orientation is telling them 'work hard' and aspire (Government official, Ethiopia).

For beneficiaries to reach graduation thresholds, social capital as well as self-confidence or 'the ability to deal with problems' are vital attributes. Projects such as the Consultative Group to Assist the Poor's (CGAP) Graduation Pilot Project ${ }^{4}$ in Tigray have revealed that providing sufficient support and coaching to build households' confidence (often called the 'X-factor' of the CGAP graduation approach) is an important enabler for graduation.

The biggest challenge we see is that most households lack confidence. There is this fear that if they engage in these activities they might not succeed. When you start a business it requires the individual to have confidence that his business will succeed. Confidence is not usually found in these households, so that is the first main obstacle (International NGO worker, Ethiopia).

In both countries women and female-headed households were considered to be performing disappointingly in terms of graduation.

Graduation from Ethiopia's FSP is meant to happen by combining PSNP with HABP, but the HABP fails to promote activities that are likely to be undertaken by female-headed households, since these either require land ownership or promote labour-intensive activities that are better suited to men.

In Rwanda, survey evidence revealed that women and female-headed households were less likely to graduate from the VUP than men and maleheaded households, leading to speculation about the reasons for this gender-differentiated outcome.

One suggestion was that women invest the VUP money in the nutrition and education of their children - they invest in the family's immediate needs - but the men buy a cow or some pigs and start to generate more income, so after a year or two they are ready to leave the VUP while the woman still needs help to feed her family (Government official, Rwanda).

There are also gender differences in terms of women's ability to take up opportunities, related to their heavier burden of care in the household and their limited 
control over resources - income and assets - within families (Development partner, Rwanda).

However, these adverse gendered outcomes are not inevitable. In other graduation projects, notably those in Bangladesh, women receive livelihood support that is designed around more gender-appropriate income-generating activities, and they perform considerably better.

\section{Beneficiaries don't want to graduate because they want to keep their benefits}

Contradicting the official narrative that participants are enthusiastic to graduate out of poverty and food insecurity, development partners, researchers and civil society representatives in Ethiopia and Rwanda conceded that many PSNP and VUP participants prefer not to graduate, since being in these programmes provides them with a regular income, subsidised or free access to services and a safety net that they do not want to lose.

From a development perspective graduation sounds good, but for the beneficiaries it is not good! Because they lose all their benefits (Development partner, Rwanda).

There is a huge benefit to being labelled category 1 or 2. You get VUP, you get 'mutuelle de santé', you get free education. As soon as you move to category 3 you lose all of this (Development partner, Rwanda).

Incentives to stay in the programme as long as possible are equally strong in the Ethiopian context, with its long history of disasters and food insecurity. Some participants apparently make strategic decisions to ensure that they will stay in the PSNP, like selling their assets before a graduation assessment is done, then buying them back afterwards.

Nobody wants to graduate. For me the PSNP is an insurance for everyone. As long as there are climate risks and disasters, people want to be part of this insurance. So these farmers want to be in the programme forever, and you have to save them from this dependency syndrome (Researcher, Ethiopia).

\subsection{Political level}

The graduation programmes in Ethiopia and Rwanda are high profile and enjoy political support from the highest level. This is generally considered as a positive factor, since it ensures that these programmes are prioritised by government officials and receive the administrative, technical and financial resources they require to operate effectively. On the other hand, with political support also comes political pressure to demonstrate success.

\section{Stakeholders interviewed in Ethiopia} acknowledged that the political discourse surrounding the PSNP equates high numbers of graduated participants with programme success. This has created an incentive structure among civil servants and local officials that favours rapid - even potentially 'premature' graduation.

\section{Politics trump evidence. So the need to deliver on political targets will trump the evidence of what is possible. The incentive is actually not to make households graduate sustainably, the incentive is to tick a box: 'Yes, we have achieved that target' (Development partner, Ethiopia).}

While some perceived that premature graduation was caused by political pressure, others argued that it was the result of miscommunication concerning graduation targets between higher administrative levels and woreda (district) officials. While the federal level and the regions saw graduation figures as recommendations or guidelines, woredas interpreted these as rigid quotas.

\section{The federal level gives 'guidance numbers' for how many people should be graduated, but at woreda level they translate it as a quota, as something that has to happen. Even if not obligatory from above they are perceived as being obligatory from below. That has affected the whole sustainability issue (Development partner, Ethiopia).}

As a consequence, it is impossible to calculate how many PSNP ex-participants have genuinely surpassed the graduation thresholds and how many have been 'exited' from the programme due to a 'systematic coercion to graduate people'.

Political pressure and graduation targets also create perverse financial incentives at the woreda level. On the one hand, achieving high graduation rates is associated with being a 'successful' woreda. On the other hand, local officials have little incentive to graduate people from the PSNP, as this will reduce the budget 
that the woreda receives from the programme when participant numbers fall. This puts them in an anomalous position, where success is 'punished' with losing funds.

The woredas are essentially reliant on the PSNP for administrative recurrent budgets, so what is the incentive of the administration to actually deliver the programme effectively? So you enter into these really perverse incentives that undermine the integrity of the programme (Development partner, Ethiopia).

After the PSNP's first five-year cycle, when only limited graduation had been achieved, it was acknowledged that the initial graduation targets or quotas were too ambitious, and they were relaxed during the second phase. Nonetheless, expectations around graduation remain high. One of the authors participated in a workshop in Addis Ababa where a senior government official complained: 'The PSNP has failed. We are supposed to be graduating millions of people and instead we just see the numbers of beneficiaries increasing every year.'

Rwanda seems to be following the opposite trajectory to Ethiopia. In Rwanda, graduation was not initially a political imperative. Although the VUP was expected to contribute to national poverty reduction goals, it was seen as just one intervention among many. Programme managers in government were sympathetic about the challenges poor people face, and they were realistic about what could be achieved.

There is no pressure to graduate. We are trying to make it happen organically. You are talking about illiterate people who are defeated and think they are doomed - 'we were born poor and we will die poor'so they do not believe inside themselves that things can happen to get them out of poverty. We try things, we try to be innovative, we have some passion to graduate people out of poverty, but we don't put targets on how many people will graduate by when (Government official, Rwanda).

However, as the VUP scaled up by adding new sectors from each district each year, questions were asked about how long the first cohort of sectors should continue to receive support.

There was a very big debate about graduation when VUP kept expanding and adding new sectors each year but not leaving old sectors. When the 4th cohort was added the question was asked: why are we still putting support into the 1st cohort sectors? What are we doing wrong? (Government official, Rwanda).

Because the government of Rwanda has a strong commitment to poverty reduction, and because the VUP was seen as a successful and popular social protection programme, the 2nd Economic Development and Poverty Reduction Strategy (EDPRS-2) highlights the VUP, and the Social Protection Sector Strategy has an annex with target numbers to be graduated from the VUP for the next five years. Of course, a more prominent place for graduation on the policy agenda through the EDPRS-2 also increases the pressure to deliver results, which could lead to similar adverse consequences as in Ethiopia, if not treated with caution.

The new EDPRS sees graduation as central to development, so there is huge political pressure to graduate VUP beneficiaries in the next five years. Community leaders have to show progress because they all have 'imihigo' [performance plans], so they will have to graduate people (Development partner, Rwanda).

\section{Conclusion}

The interviews we conducted in Ethiopia and Rwanda confirmed that the position different actors take on the appropriate functions of social protection programmes often reflects their ideological perspective - crudely, whether they see social protection as a temporary safety net linked to a poverty reduction agenda, or if they see social protection as a permanent feature of social policy and a tool for achieving social justice. We draw conclusions from our research at the conceptual, operational, strategic and political levels.

Conceptually, many stakeholders saw no contradiction between the 'protection' and 'promotion' functions of social protection. The consensus opinion was that it is possible to put in place a safety net against poverty and simultaneously graduate people out of poverty, using a toolkit of complementary instruments. Stakeholders who emphasise growth and poverty reduction outcomes see graduation as an imperative: programmes should set targets for 'exiting' participants off social assistance, and if these targets are not achieved the programme has failed. Conversely, stakeholders who assign 
an intrinsic value to guaranteeing a minimum subsistence to all poor and vulnerable citizens and residents at all times are more concerned with establishing a comprehensive and sustainable social welfare system, and ensuring that an effective safety net is installed against future shocks.

Operationally, the tension between 'protection' and 'promotion' objectives has been resolved in both Ethiopia and Rwanda by a bifurcated 'twintrack' approach - providing differentiated support to different population sub-groups, depending on their perceived 'graduation potential': long-term social assistance for poor people with limited graduation potential, short-term social assistance plus livelihood support to poor people who are expected to become self-reliant if they receive an appropriate package of productive resources that includes assets, training and access to microfinance. In other words, social protection should provide a permanent safety net for some and an opportunity to graduate out of poverty for others. One key implication for the design and implementation of graduation programmes is that a careful analysis is needed of the 'enablers' and 'constraints' to graduation in each context - there is no blueprint 'graduation model' that can be applied with equal probability of success across very different countries, regions and livelihood systems.

One strategic challenge identified by many stakeholders is to shift expectations away from seeing social protection programmes like the FSP and VUP as instruments for achieving food security and poverty reduction in their own right, towards locating these programmes in a sequenced suite of support provided to poor and

\section{Notes}

* This research was conducted under a programme partnership between Irish Aid and the UK Institute of Development Studies on 'Hunger Reduction and Climate Change Adaptation', which brings together research and capacity development with policy, programmatic and influencing know-how to support action that more effectively reduces poverty and injustice. Financial support from Irish Aid is acknowledged. A preliminary version of this article was presented at the international conference on 'Graduation and Social Protection’, in Kigali, Rwanda, 6-8 May 2014. vulnerable people. The policy implication is that graduation should be implemented not in terms of 'exiting out of' all social protection programmes but rather by 'graduating into' complementary social and economic programmes. Some donor agency representatives argued for introducing or strengthening mechanisms that allow programme participants to move smoothly from informal to formal social protection (in other words, from social assistance to social security) or from informal to formal employment (from public works to selfemployment to wage-earning jobs). Only if opportunities for these transitions are built into social protection interventions will sustainable graduation be possible.

Finally, it is often argued that social protection programmes need strong political support to attract the resources they need, but in the case of graduation programmes the challenge is sometimes not too little political support, but too much. Political pressure can compromise rather than promote genuine and sustainable graduation outcomes, and there is a risk that unrealistic expectations can cause political support to wane if large-scale graduation is not achieved within a relatively short time frame. Typically, there is more political support for graduation programmes than for safety nets, with government officials expressing concerns about the fiscal affordability of permanent programmes and about encouraging 'dependency' rather than self-reliance. Politicians and bureaucrats need to be convinced that a permanent, comprehensive social protection system is a positive symbol of progress and development, and that graduation is a realistic objective only for part of the eligible population.

1 Although the overall programme is the Food Security Programme (FSP), its dominant component is the Productive Safety Net Programme (PSNP) - which includes Public Works and Direct Support as sub-programmes - and 'FSP participants' are more often than not referred to as 'PSNP beneficiaries'. This article also uses these two terms interchangeably.

2 More details on the methodology, including the interviewees and the semi-structured questionnaire, are provided in the research report (Devereux and Ulrichs 2014). To protect the anonymity of respondents, the names of 
individuals and the organisations they work for are not listed in this article, and no names are attributed to any direct quotations.

3 A third research question explored how stakeholders understand graduation conceptually (what does graduation mean?) and operationally (how are participants graduated?). For reasons of space these findings are not reported here; interested

\section{References}

Almeida, R.; Arbelaez, J.; Honorati, M.; Kuddo, A.; Lohmann, T.; Ovadiya, M.; Pop, L.; Puerta, M. and Weber, M. (2012) Improving Access to Jobs and Earnings Opportunities: The Role of Activation and Graduation Policies in Developing Countries, Social Protection and Labor Discussion Paper 1204, Washington DC: World Bank

Barrientos, A. (2010) Social Protection and Poverty, Social Policy and Development Programme Paper 42, Geneva: United Nations Research Institute for Social Development (UNRISD) BRAC (2013) An End in Sight for Ultra-poverty: Scaling up BRAC's Graduation Model for the Poorest, Briefing Note 1: Ending Extreme Poverty, Dhaka: BRAC

Devereux, S. and Teshome, A. (2013) 'From Safety Nets to Social Protection System: Options for Direct Support Beneficiaries of Ethiopia's Productive Safety Net Programme', in Dessalegn Rahmato, A. Pankhurst and readers are referred to the research report (Devereux and Ulrichs 2014).

4 CGAP and the Ford Foundation launched ten 'Graduation Pilot Projects' across the world, adapting BRAC's 'graduation model' from Bangladesh to different contexts. One of these ten ran in Tigray, Ethiopia, 2010-12 (http://graduation.cgap.org/pilots/ethiopiagraduation-pilot/).

J-G. van Uffelen (eds), Food Security, Safety Nets and Social Protection in Ethiopia, Addis Ababa: Forum for Social Studies

Devereux, S. and Ulrichs, M. (2014) Stakeholder Perceptions on Graduation in Ethiopia and Rwanda: A Report for Irish Aid, Brighton: IDS

FSCB (Food Security Coordination Bureau) (2007) Graduation Guidance Note, Addis Ababa: Ministry of Agriculture and Rural Development, Government of Ethiopia

Kidd, S. (2013) 'The Misuse of the Term "Graduation" in Social Policy', Pathways Perspectives 14

MINALOC (Ministry of Local Government) (2011) Vision 2020 Umurenge Programme - Exit and Graduation Briefing Paper, Kigali: Ministry of Local Government, Government of Rwanda Sabates-Wheeler, R. and Devereux, S. (2013) 'Sustainable Graduation from Social Protection Programmes', Development and Change 44.4: 911-38 